\title{
Caregiver perspectives of risk and protective factors influencing early childhood development in low-income, urban settings: a social ecological perspective
} Draper $\mathrm{CE}^{* 1}$, Cook $\mathrm{CJ}^{1}$, Howard $\mathrm{SJ}^{3}$, Makaula $\mathrm{H}^{1}$, Merkley $\mathrm{R}^{2}$, Mshudulu $\mathrm{M}^{1}$, Tshetu $\mathrm{N}^{1}$, Scerif $\mathrm{G}^{4}$.

${ }^{1}$ SAMRC/Wits Developmental Pathways for Health Research Unit, School of Clinical Medicine, Faculty of Health Sciences, University of the Witwatersrand, Johannesburg, South Africa.

${ }^{2}$ Department of Cognitive Science, Carleton University, Ottawa, Canada.

${ }^{3}$ Early Start and School of Education, University of Wollongong, Wollongong, NSW, Australia.

${ }^{4}$ Department of Experimental Psychology, University of Oxford, Oxford, United Kingdom. *Corresponding author

\begin{abstract}
South Africa is a diverse country characterised by stark inequalities that undermine early childhood development (ECD). Caregivers of young children play a critical role in providing nurturing care to mitigate against risks to ECD. The aim of this qualitative study was to explore caregivers' perceptions of factors influencing ECD in a low-income, urban South African setting, from a social ecological perspective. Individual interviews were conducted with 15 caregivers of 3-5-year-old children from three low-income communities in Cape Town, and a reflexive thematic analysis approach was adopted. In the family and home context, caregivers spoke about their role in developing, nurturing, providing, protecting, and disciplining their children. Risks in this context included low socioeconomic status, dysfunctional relationships, and caregiver mental health; resources related to early learning and social support. In the preschool / school context, caregivers discussed the value of early
\end{abstract}


learning, and priorities for selecting early childhood care and education settings. In the community context, risks included violence and crime, whereas resources mentioned were social support, community programmes, and infrastructure. Caregivers also shared perceptions of the community's role in their child's development. These findings should be considered in light of the structural violence experienced in low-income settings in South Africa in order to holistically address risks and amplify protective factors for promoting ECD and the provision of nurturing care in these settings.

\section{Highlights}

- Caregivers are nurturing, resilient and resourceful.

- Caregivers see their role in promoting early childhood development.

- The impact of violence on young children can be underestimated.

\section{Keywords}

caregivers, low-income, social ecological model

\section{Acknowledgements}

The authors would like to thank the research participants who took part in this study. This work was supported by the British Academy for the Humanities and Social Sciences [grant number ECE190051]. 


\section{Introduction}

In low-income settings, the development of young children can be compromised due to accumulated adversities faced in these settings (Black et al., 2017). The provision of nurturing care in early childhood, and across the life-course (Tomlinson, Hunt, et al., 2021), can mitigate against these risks to development. Parents, and other adult caregivers, play a critical role in providing all dimensions of nurturing care: health, nutrition, responsive caregiving, safety and security, and early learning (Britto et al., 2017). An ecological perspective can help to understand how the provision of nurturing care can positively impact on developmental trajectories, through enhancing resilience and diminishing the detrimental influence of accumulated adversities (Tomlinson et al., 2019; Tomlinson, Hunt, et al., 2021). Bronfenbrenner's social ecological model of human development (Bronfenbrenner, 1977) provides a meaningful framework for understanding how child development is influenced by the family and community environments, and broader social, policy, and historical factors.

The application of a social ecological perspective to understanding factors influencing early childhood development (ECD) is particularly relevant in South Africa - a diverse country characterised by stark inequalities that undermine ECD. The social ecological perspective provides insight into the relationship between individuals, families, communities, and society, acknowledging that these relationships are complex and that they impact on development (Department of Social Development, 2021). Common features of the family and community environment in low-income South African settings include unemployment, poverty, crime, violence, substance abuse, and gender-based violence (Department of Social Development, 2021). Food insecurity and hunger are also pervasive challenges, with $27 \%$ of children under five stunted (Hall et al., 2019). Broader social influences include income inequalities, and the legacy of apartment systems such as spatial injustice and residential segregation that perpetuate the cycle of poverty. Many children are raised by single parents 
(or grandparents), and the burden of caregiving is placed predominantly on women, who have been the worst affected by the COVID-19 pandemic (Spaull et al., 2021). The gendered nature of caregiving in South African families creates barriers for the economic advancement of women, given that many have limited care support, thus emphasising the crucial role of support networks - both family and community - for women playing caregiving roles (Department of Social Development, 2021).

These contextual realities impede the provision of nurturing care in low-income South African settings (Hall et al., 2019). While there are numerous initiatives to promote nurturing care in the first 1,000 days, this is not necessarily the case for preschool-aged children (3-5 years). This age group engages less frequently with health services (and generally only if they are sick), and receives less attention regarding nutrition, compared to the emphasis on breastfeeding in infancy. While there are programmes (mostly non-governmental) supporting caregivers of children in this age group, early childhood care and education (ECCE) services are the main vehicle for care, education, and information relating to the early years. However, ECCE services are not financially accessible to all, since they are not state-subsidised, nor of high quality (Hall et al., 2019). Furthermore, ECCE services are faced with resource challenges, and working conditions for practitioners are stressful (Vorster et al., 2016). ECCE attendance levels for South African children aged 0-6 years are reported to be at $36 \%$ (slight decrease from pre-pandemic levels of 39\%), with the pandemic negatively affecting caregivers' ability to afford ECCE fees (Wills \& Kika-Mistry, 2021). Attendance of children 3-5 years of age is closer to $70 \%$ (Hall et al., 2019), with those attending generally limited to 1-2 years of ECCE. This leaves almost a third of children starting formal school with no preprimary education, which has considerable implications for curriculum expectations at the start of formal schooling. Given these challenges, it is essential to consider factors 
influencing the provision of nurturing care, and hence promotion of ECD, for preschool-aged children in general, especially for those children who do not access ECCE in South Africa.

Research on the influence of dimensions of nurturing care on ECD in South Africa, such as the Birth to Twenty Plus cohort study, has established the influence of early caregiving for developmental outcomes, specifically factors such as maternal responsiveness, cognitive stimulation, and learning opportunities (Slemming et al., 2021; Trude et al., 2021). Findings from this cohort study also highlighted the intergenerational transfer of socioeconomic and health inequalities (von Fintel \& Richter, 2019), which negatively impact nurturing care, and hence ECD. There have been few studies investigating in depth the characteristics of nurturing care in the preschool age group, apart from some testing the feasibility of a nurturing care intervention with caregivers of children in this age group (Draper et al., 2019; Klingberg, van Sluijs, Jong, et al., 2021).

Other research in low-income South African settings has highlighted poor ECD and early learning outcomes (Dawes et al., 2020; Draper et al., 2012; Lessing \& Witt, 2005; Naudé et al., 2003; Pretorius \& Naudé, 2002; Spaull \& Kotze, 2015). However, precursors of learning - namely, executive functions - have been shown to be at or above age expectations in these low-income settings (Cook et al., 2019; Howard et al., 2020), suggesting that these young children are equipped with the cognitive capacities that support effective learning, but this opportunity is not being exploited in early learning and education contexts. Furthermore, despite the challenges with ECD in South African contexts discussed above, there may be factors within the home and community uniquely promoting these cognitive capacities (Cook et al., 2019; Howard et al., 2020). More recent research has further investigated associations between executive function, learning and early learning contexts in preschool-aged children from very low-income settings, who were not attending an ECCE setting. Initial findings indicated no significant relationship between the simple frequency of learning activities 
within children's home learning environment and their early numeracy skills [reference blinded], or between children's self-regulation abilities and their exposure to community violence [reference blinded]. As such, further research is required to identify qualitatively what other social ecological factors influence ECD in these contexts.

Previous research in South Africa has explored caregivers' perceptions relating to multiple components of nurturing care. This has included health and nutrition in terms of healthy behaviours (Draper et al., 2017, 2022; Klingberg, van Sluijs, \& Draper, 2021; Tomaz et al., 2020), health more generally (Daniels et al., 2016), obesity in young children (Klingberg et al., 2020), and safety of older children (Simons et al., 2018). These findings have highlighted the role that caregivers play in providing for and protecting their children, and suggest that caregivers' perceptions, particularly related to health and nutrition, should be considered from a holistic developmental perspective. Consideration should also be given to caregivers' perceptions regarding the role they play in their child's development. There have been no published studies that have explored South African caregivers' perceptions of the various factors influencing ECD, applying a social ecological approach. Some have qualitatively explored children's experiences of violence (Breen et al., 2015; Shields et al., 2008), and one explored preschool children's experiences of play in a low-income community, highlighting the resourcefulness of their play in this setting, as well as the influence of context (Bartie et al., 2016), yet even these did not capture caregiver perceptions. The aim of this study was therefore to explore caregivers' perceptions of factors influencing ECD in a low-income, urban South African setting, from a social ecological perspective. This level of understanding is vital, if we are to optimise education and intervention by meeting caregivers at their current priorities, challenges and levels of understanding relative to contemporary evidence. 


\section{Methods}

\section{Study design and participants}

The exploratory qualitative study formed part of a larger study investigating barriers and protective factors for early learning in young children from low-income settings in Cape Town, South Africa. Ethical approval for this study was obtained from the Human Research Ethics Committee (Medical) at the University of XXX (ref: xxxx). Primary caregiver-child pairs were recruited for the larger study through a community-based organisation that works with families in low-income settings in Cape Town, particularly those families with young children who are not accessing ECCE services. Recruitment was facilitated through the organisation's 'home visitors', and research assistants contacted caregivers telephonically in May 2020 to recruit them for the main study, when children were 3-5 years old. At the time of data collection for this qualitative study in 2021, some of the children were accessing ECCE services, or had started their reception year ('Grade R') at primary school, which is government subsidised. Caregivers were all over the age of 18 years; no upper age limit was applied since many young children from low-income settings in South Africa have a grandmother as their primary caregiver.

Following two rounds of data collection in 2020 and 2021, a sub-sample of 15 caregivers was recruited telephonically in July 2021 for this qualitative study, selecting five caregivers from three of the settings where data collection was completed. These 15 caregivers were purposively selected based on research assistants' impressions of their willingness to be interviewed and speak openly about factors influencing their child's development. All participants gave written informed consent for their participation, and for the interview to be audio-recorded. Participant details are presented in Table 1. 
Table 1: Participant details

\begin{tabular}{|c|c|c|c|c|}
\hline Participants $^{\mathrm{a}}$ & $\begin{array}{l}\text { Relationship to } \\
\text { child }\end{array}$ & $\begin{array}{l}\text { Caregiver } \\
\text { age }\end{array}$ & $\begin{array}{l}\text { Child } \\
\text { age }\end{array}$ & $\begin{array}{l}\text { Child attending } \\
\text { ECCE }\end{array}$ \\
\hline $1-$ Zelda & Mother & 36 & 6 & Gr R \\
\hline 2 - Lee-Ann & Mother & 34 & 6 & Gr R \\
\hline 3 -Olwethu & Mother & 33 & 4 & Preschool \\
\hline 4 - Siya & Father & 53 & 5 & Gr R \\
\hline \multirow[t]{2}{*}{$5^{b}-$ Khuselwa } & Aunt & 32 & 6 & Preschool \\
\hline & Mother & & 5 & Preschool \\
\hline 6 - Unathi & Mother & 38 & 4 & Creche \\
\hline $7-$ Velma & Grandmother & 48 & 5 & Gr R \\
\hline 8 - Nosipho & Grandmother & 54 & 6 & Preschool \\
\hline 9 - Eunice & Mother & 30 & 5 & Gr R \\
\hline $10-$ Yolisa & Mother & 29 & 5 & No \\
\hline 11 - Linda & Mother & 38 & 6 & Gr R \\
\hline $12-$ Nadine & Mother & 29 & 5 & Gr R \\
\hline $13-$ Zintle & Mother & 31 & 6 & Gr R \\
\hline 14 - Gladys & Mother & 45 & 5 & Creche \\
\hline $15-$ Candice & Mother & 37 & 5 & Gr R \\
\hline
\end{tabular}

\section{Study sites}

Participants were recruited from three low-income communities within Cape Town. Two of these communities have a high proportion of informal housing, with pervasive overcrowding. High rates of unemployment, food insecurity, alcohol abuse, crime and HIV are challenges in these communities. The third community has a mix of formal and informal housing, and is 
also densely populated. Drug abuse and gangsterism are major challenges in this community, along with high unemployment, crime, and food insecurity.

\section{Data collection}

Individual interviews were conducted by local, trained research assistants who were able to converse with participants in their home language. Guide questions were developed by the research team, with input from local research assistants to ensure their contextual relevance and the extent to which questions could easily be translated into local languages. Drawing on the social ecological model, the questions broadly addressed factors within the family/home and community environments that influence ECD in these settings. Given the broader focus of the larger study, these questions focussed to some extent on early learning, but were intended to be flexible enough to accommodate discussion about the other dimensions of nurturing care, namely health, nutrition, responsive caregiving, safety and security. These questions are provided as supplementary material.

All participants received a shopping voucher (value of approximately US\$7) as a token of appreciation for participating in the interview. Interviews in the first two communities were conducted in participants' homes. In the third community, interviews were conducted at the offices of the community-based organisation due to safety concerns relating to visiting homes; participants were reimbursed for their travel costs. The interviews ranged in length from 15-45 minutes, and all were audio-recorded. Recordings were translated into English where necessary and transcribed verbatim (in English) for analysis.

\section{Data analysis}

A reflexive thematic analysis approach was adopted to analyse the interview data (Braun \& Clarke, 2021) since this flexible approach was suited to the research question - to explore caregivers' perceptions of social ecological factors influencing early childhood development. The analysis process was largely deductive, as coding and theme development was informed 
by the social ecological model. Certain 'layers' of the social ecological model were designated as the main themes. Although the macrosystem (social and political context) and chronosystem (historical context) were included in the framework, these were not used as themes in the analysis, but rather were included to situate the findings within a broader South African context, which will be addressed in the discussion.

After reading through the transcripts, sub-themes were added to these thematic categories based on the data. A thematic framework was then developed, as shown in Figure 1, and co-authors provided feedback on this framework. Codes were then developed according to the themes and sub-themes in this thematic framework, and these were then applied to the interview transcripts for data analysis, using MAXQDA 2020 (VERBI Software, 2019). Quotes for each sub-theme were extracted, and these were summarised under the relevant social ecological 'layers' (main theme). Exemplar quotes were then selected for each sub-theme, and these are presented with the results. The results are presented according to the following themes: child characteristics, behaviours and activities; family and home context; preschool / school context; and community context.

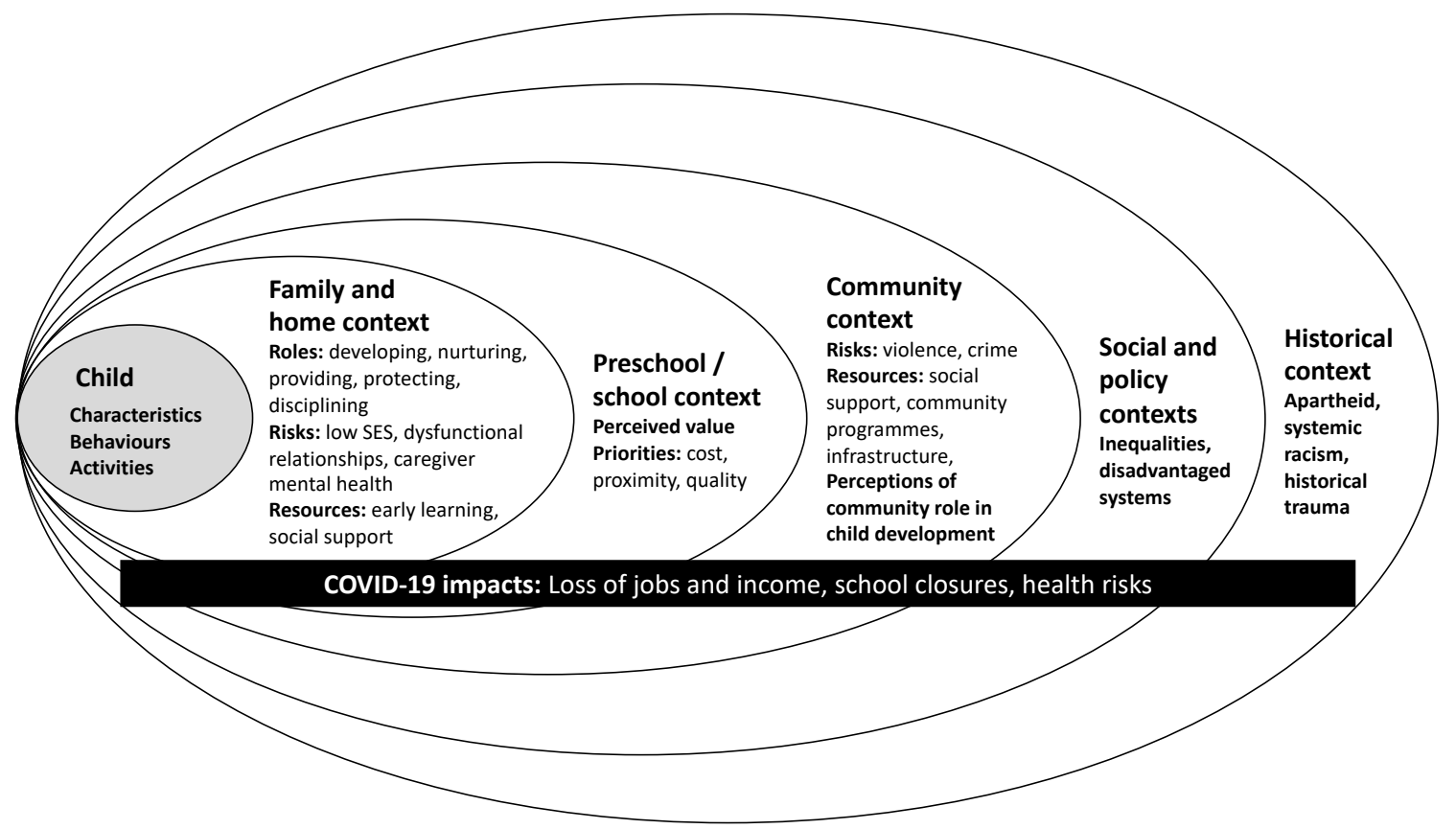

Figure 1: Social ecological factors influencing early childhood development 
Regarding data quality, Tracy's (2010) "Big-Tent" criteria provide guidance for this study: worthy topic, rich rigour, sincerity, credibility, resonance, significant contribution, ethical, and meaningful coherence (Tracy, 2010). Literature presented in the introduction has highlighted the importance of early childhood development in low-income South African settings, and that there is a need to capture caregivers' perceptions on this topic in order to intervene in a contextually appropriate manner. Appropriate sample, data collection and analysis methods were employed to contribute to the rigour of the study, and these methods have been described transparently, along with study limitations and strengths of highlighted in the discussion. The quotes included attempts to meaningfully present participants' voices and experiences, and the themes have been described in detail to lend credibility to the findings. The application of the social ecological model enhances the meaningful coherence of the study and its contribution to the literature. Lastly, the study was conducted in an ethical manner that engaged with participants in a contextually appropriate way.

\section{Results}

\section{Child characteristics, behaviour, and activities}

The majority of participants described their child in positive terms, using terms such as “respectful”, “clever”, “humble”, “well behaved”, “well mannered”, “very excited”, "always happy", "talkative”, “bright”, “obedient”, "bubbly”, and "fast learner”. While some mentioned more challenging characteristics, such as "hyperactive", "naughty", and "wasteful", these were often framed as being normal for children.

I am happy with her progress and everything that she does and even her mischiefs are just as normal as any other child. (Eunice)

They are naughty, they are wasteful because they are boys. (Khuselwa)

A small number of participants mentioned that their child had behavioural challenges, including being disruptive or being aggressive with other children. For some, this was linked 
to issues in the home or what children were learning in the community, while others were not able to explain the child's aggressive behaviour.

She said she doesn't want anyone to talk about her daddy, as soon as she hears someone talk about him then the levels drop, she is angry, she swears at you, she stab the other children in the arm you know that. (Lee-Ann)

When he plays with his friends outside, because some of his friends are physically violent, there are some that are bullies and physically violent, so then he'll come home and say to me so and so hit me, this one hit me or whatever; then he says you see now mama I'm also going to hit them. (Gladys)

I don't know why what to say about his behaviour but he just doesn't listen, he is like a child that grows up under a violent background. (Khuselwa)

These responses suggest that, for the most part, these participants consider their children's development and adjustment to their environment to generally be within the normal range. Although a few participants spoke about things that their child battles with at preschool or school, none of the participants discussed these at length.

In terms of children's preferred activities, participants' responses were mixed. This included outdoor and indoor play, playing on their own versus with siblings or other children in the neighbourhood (more common than solitary play), screen time (especially cartoons) and more active games, imaginary play and reciting nursery rhymes, singing and reading. Some participants mentioned children playing with or using resources, like cars, dolls, balls, scissors and books. From participants' responses, it seems that children are resourceful in their play (in a resource-limited setting), and that most of their children go about their day somewhat autonomously (apart from attending preschool or school), whether it is playing outside or watching television when they want. This could be suggestive of limited parental supervision, although later themes exploring caregivers' protective nature suggest otherwise. 
He'll go to the park and play with them there at the park. When he comes back, he says he's hungry, he eats and then he leaves again; and he says mama I'll be back, and then he's gone you won't find him again. (Gladys)

[Name] likes chatting and playing, but in most cases, she likes watching cartoons, you will never hear her say a word. She will be quiet until the cartoons are finished. We would then let her be. (Zintle)

She likes playing with her friends that are near to us, they play here in the yard. And they like to play with sand, and dolls and water. (Linda)

\section{Family and home context}

\section{Roles}

Developing: In terms of the roles played by caregivers, participants spoke most frequently about their role in their child's development. A few specifically acknowledged their responsibility for their child's development and learning, while more mentioned various developmental activities that they engaged in with their child. These included helping to write and colour in, counting, reading together, talking about what they learnt at school, doing homework from school.

It is my responsibility to sit with my child and look what he is doing, that is my responsibility not to look around and talk to other people, it is wrong. (Nadine) She likes when I help her colour in and write and spell words for her out, when I help with her homework... I like to sit and read to her. (Candice)

I help them most as I can in homework. I'm very good with that because I'm always there when the homework must be done. (Velma)

I think that it's something that I feel if I don't take a role then I don't see what success there shall be, I need to take a role and be actively involved so that he can also be encouraged and be able to move forward. (Siya) 
A few participants spoke about their aspirations for their child to do activities that are stimulating and beneficial, e.g. sports, going on outings; some spoke about aspirations more generally, in terms of wanting their child to succeed. Overall, these responses appear to highlight the value that participants place on their child's development, and taking opportunities to optimise this development.

I wanted [name] to have activities that he can do, something like sports or maybe karate here in the hall or at school...If there's money to be taken out then I'll take out money every month so he can train, rather than have him in the streets where they'll be hitting each other and brawling... (Gladys)

I think if we can take them out more often and visit, because they love animals. You can see when they see them in the books, or maybe take them out to the movies...those are the places they wish to visit... That place where you go underneath ... aquarium ...I think they will learn a lot if they go there. Or maybe if they go to Table Mountain or get on the red bus. (Khuselwa)

I want a lot of things for her. I want her to also succeed in life... what I didn't get and didn't do, I want her to get it and do it for herself. (Linda)

Nurturing: Participants spoke about their interaction and relationship with their child, mostly in positive terms, mentioning that they love each other and get along. Despite the typical challenges of parenting, it would appear that these relationships are generally nurturing, supported as well by the positive terms used to describe their children mentioned above.

I don't want to lie to you, we do not have issues. We get along very well... (Zintle) We are good, I love her a lot. The others love me as well, but she is at an age where she needs attention and get a mother's love. (Unathi)

We have a very good relationship, I don't want to lie, cause he is the one that loves both his parents, he loves me the most. He loves me and I also love him. (Yolisa) 
Providing and protecting: Linked to this nurturing role, participants' responses indicated that they also feel a responsibility to provide for and protect their child (and likely other children in the household). Given the challenging circumstances in which they live (including violence and crime, discussed further below), this role is significant. Provision included seeing to their basic needs, and often seemed to include stretching their resources as far as possible. This resourcefulness could be linked to how some participants articulated "getting by" or "doing fine", and this may positively influence children's resourceful in play, mentioned earlier.

And they eat a lot so sometimes there is not, I will sometimes make something out of nothing. (Velma)

Related to this, many participants expressed the desire and/or need to protect their child from their socioeconomic circumstances, so that as far as possible, they did not have to go without. In some cases, this was expressed as wanting to protect their child from seeing how they, as a caregiver, suffered to provide for them.

If there are challenges, I'm trying to figure out which way to go. How is the easiest way to make them not affected by it? ...I always make sure that they don't feel out between other children. (Velma)

It has never come to that stage as yet, for a child to even notice it... we live a very simple life, I don't know how to explain this, but when we don't have something, we don't have it, and a child must understand that we don't have...(Khuselwa)

Protection also included keeping them inside and thus away from violence and crime in the community, which seemed difficult due to some children's natural curiosity and their desire to play outdoors.

Ja, sometimes we allow him to go play with other kids maybe in the road, but not for long then come in again because he got a curfew. We put him on a curfew. (Zelda) 
I don't want her anywhere near violence. I don't even want her to see it, she will hear it that is a gun shooting I will say that is good for you stay in the house people fight. I'm not going to take her out and she must see how the people are fighting how they are stabbing each other. I don't want her to grow up like that. I keep her in the house...she makes me mad when she sees the door is open and she runs, she doesn't tell me I'm going to go and play there now... A few years ago there was a lot of rape of children so that I'm very scared, she will always be in the yard. (Linda)

One of the participants who experienced depression (discussed further below) expressed the desire to protect and provide for her child, with her child's wellbeing as a strong motivation. [I'm glad you are taking care of your mental health.] I must because of the children...they are my motivation because if it were not for them, I wouldn't be here. Sometimes the child is what keeps you alive because what is going to happen to the child if you are not there? (Lee-Ann)

Disciplining: Discipline was discussed by all participants, and just over half of them spoke about physical punishment as a form of discipline. Some claimed this form of punishment was necessary, while others threatened to hit their child, or stated that they would not hit their child but would shout at them. One participant contradicted herself, and for her, hitting was said to be the result of frustration. A few participants mentioned that the child's father would hit them, and one mentioned that the child was threatened with physical punishment at preschool for being disruptive.

Then I scold them, I beat them and do whatever I have to do for them to behave. (Khuselwa)

Ja, because for me it wasn't necessary for her to do that, so I had to hit her. I had to. (Lee-Ann) 
There are some challenges and I only end by promising to beat her, but I don't beat her, Ijust promise to punish her, but I don't, because she is a coward. (Eunice) Sometimes when I'm too frustrated then I will hit her... With me it looks like she can take advantage of me because I will never hit her...But her daddy will talk one word then the next will hit. (Linda)

...teacher will shout at him and say, 'hey [name], I'll hit you...' (Gladys)

Other forms of discipline included taking away privileges (e.g., toys), shouting, or talking with the child. This discipline sometimes involved another parent if they are present, although things could become complicated if there were different discipline styles.

I take things away from her when she doesn't listen. I tell her she can't play with this. Or you can't have any money, or you can't have this if you don't do this. I tell her I'll give you that thing if you don't do it I'll not give it to you. (Candice)

When he is naughty, we curb him, like he can't use the phone, there is no TV, there is washing time then you go sleep...he can't go play with the boy in front or you can't ride your bike we curb him there. (Zelda)

Related to discipline, only one participant specifically spoke about routines and boundaries with her child, and this was in the context of enforcing boundaries with the child's father, who is in prison and perceived to be a negative influence.

I told him we have got a structure at home, if it is his 5pm bath time then he knows that he is in bed he can watch TV till 8. Now ifyou phone after 8 I'm not going to wake a child up and give the phone to the child... I told him I don't care that is my rules and that is our rules. (Zelda)

\section{Risks}

Low socioeconomic status: Since the participants were recruited from low-income settings, it is assumed that they would experience challenges related to finances, employment and food 
security. While there were a couple of participants who did not feel that they experienced resource challenges, most participants attested to these challenges, even if they tried to minimise them. As anticipated, these related to limited income in the household, including a reliance on social support grants, and unemployment. Some caregivers spoke about how this impacts their child, while others tried to minimise the impact on their child by encouraging them to accept the situation.

I have never had such challenges because it has not become that bad, even though we are struggling here and there, we try that it does not affect kids that much, and we also teach them that if we don't have money, then we don't have, and that they should wait, and they will get it when we have it. (Khuselwa) I would like him to go to school but right now we don't have money to take him to school, because we have too many problems and only one person is working, and he is not earning enough salary. He also has children with the other woman and the woman expects him to maintain the children. (Yolisa) My mom is the only one that is working in the house, and she gets a pension. But she only helps out now and then, but the pension and I get the child grant that helps. But other than that we are fine. (Lee-Ann)

Based on participants' responses, it was evident that many of these socioeconomic challenges were exacerbated by COVID-19, and that the pandemic had a detrimental socioeconomic impact. This included job losses, heightened food insecurity, as well as disruptions to early learning activities. A few participants spoke about what their child had learned about COVID-19, and also about the negative effect of COVID-19 on community trust.

I think the fact that I don't work cause then you get to see that certain things are running out and you have no other way to replenish... I am no longer working, cause most of the companies don't offer employment. So COVID. (Eunice) 
...there are a lot of challenges that they go through ...people are giving food. Then the one child pushes the other child then you must make them understand there was not enough...the community must help with the children but the community these days because of the COVID they don't trust each other... (Velma)

Because with the COVID the children don't learn because the one week they are at school the other week at home. They don't it isn't on for me because my daughter is getting so lazy, she cried this morning. I had to keep her at home yesterday because she has, she was sick... she will be like 'oh put a mask on, or don't talk to me, there is COVID, really’. (Lee-Ann)

Dysfunctional relationships: Just over half of the participants reported on dysfunctional family relationships. Four of the female participants mentioned that the father of their child was absent and/or uninvolved in the child's life, although some said that he played a minimal role, such as providing finances. Three of the female caregivers spoke about the child's father being in prison or involved in a court case. One caregiver, the grandmother of the child, reported that the child's mother had substance abuse issues.

Yes, it does have an effect because he would be away for two months and she [child] would ask of his whereabouts, I would then have to make up an excuse... He parents when he feels like it basically. (Olwethu)

I know for a fact that he [father] is in prison, but he is still on drugs... He likes to beat his ladies up... and he is going to do it in front of my son...He [child] might see a female and might attack the female... And now he is bigger, now he is going to see and that is our fear... He told us last week they had career day at the school and then we ask him what does he want to be? And he told us he wants to be a detective. So, we asked him why a detective? He said 'no, because when his daddy is naughty again, he can go and pick him up and put him again in prison'. (Zelda) 
The mother of the child is on drugs, so for me it is heavy... she doesn't respond as a mother...my daughter, her mother, is not working it is not easy. (Velma)

Caregiver mental health: Two participants spoke about experiencing depression (and potentially anxiety), to the extent that they were hospitalised and are now on anti-depressant medication. For both individuals, their challenging circumstances at home contributed to the depression.

Depression... if I think a lot and start feeling pain, I really do get sick, and I end up feeling stressed. The issues of making sure that the children are well, the fact that there is no money, if I start to think about those things, I get sick. And I even end up in the hospital because of overthinking...I am on medication. (Yolisa) Because of him [father] I had a nervous breakdown I ended up in hospital...I'm on the anti-depression tablets. (Lee-Ann)

\section{Resources}

Early learning: Overall, it appeared that resources in the home for early learning were limited. Participants most frequently mentioned having books for their child to read, although these were mentioned by less than half of the participants, which is consistent with quantitative data collected in the larger sample [reference blinded]. The use of phones for educational activities was also mentioned by some participants, and a few mentioned using a laptop computer, a tablet or the television for educational purposes. Mentioned less frequently were resources for writing, colouring in, puzzles, building blocks and toys, such as Lego. A couple of participants mentioned not having resources to teach their child counting, but some mentioned using other resources for this.

... she doesn't have any [educational toys] and she likes writing. You can see when looking at her that she is not a child that should be playing outside as she would be using her sister's old books and she would sit the whole day writing. (Zintle) 
I bought colouring books for him as well. Every day he will write his name for me and the ABC, numbers mommy said teacher said I must do this. (Nadine)

We don't have things for counting, we sometimes count with hands, or we use pencil to count with them, but we don't have anything else to use for teaching them. (Yolisa) We do it on the app store I download the stuff there and I read it for her and she tells me what the shapes, sizes, colours, height, length and stuff like that. (Lee-Ann)

Social support: Most participants spoke about some form of social support they received from family members (apart from the other parent), in terms of raising their child and in some cases, promoting their development. This most often included siblings, but nieces/nephews, aunts/uncles, grandmothers were also mentioned. A few participants either did not mention social support, or stated that they had no other support from other adult family members, including from the father of the child.

He [sibling] loves teaching and teaching each other, they teach each other. (Yolisa) My daughter is always helping me. My daughter is always in control doing the resources doing the washing, cooking or something like that making sure the clothes is ironed for school, the shoes is polished... (Velma)

Sometimes I do have but we get through it you know my mom always jumps in... She is always there. (Lee-Ann)

\section{Preschool / school context}

In general, participants seemed to value education, in terms of their child being able to attend preschool or the reception year (Grade R) of primary school (started in the year that children turn six years old). When asked about their choice of preschool or primary school for their child, the priorities mentioned often were cost and proximity, since this reduced transport costs. Some mentioned other factors relating to the quality of the school, in terms of how children are treated, discipline, work ethic, and exposure to English. 
I need to take them to a school that's close by where he'll be able to walk there by himself...one that is far away will give him problems and then there's the issue of transport where if there's no transport then it'll be difficult for the kids to get to school. (Siya)

It is free you only pay R400 from the moment she starts school then you don't pay till grade $7 . .$. And it is near to my house as well. (Lee-Ann)

I liked the way they treated children the day I went to apply. I observed other kids there, they don't need money. All children are treated as equals even when there is money needed, the principal would pay for those in need. (Zintle)

The education is good, and they are caring. It is also close by so there is no need for transport.(Unathi)

One participant mentioned that her child had a good relationship with the principal, and that she recognised the importance of her child going to the school where he was motivated to go. He's very well-liked by the principal, like a lot. So then he'll talk to [name] and encourage him to say 'you're going to go to [school name] my child, okay'... Whereas if you just take him to that [school name] that he wants to go to then he'll have the motivation to go there and be excited when the transport arrives to take him to school. (Gladys) 


\section{Community context}

\section{Risks}

Violence, crime: Many participants spoke about the challenges of violence and crime in their community. This included gangsterism, shootings, fighting, theft, rape, kidnapping, and physical bullying by older children. As mentioned earlier, participants mentioned trying to protect their child from these things, but some acknowledged the negative impact that the community violence has on their child.

Gangsters they fight every day. They shoot Saturday a boy dead in front of the house. (Nadine)

The thing with the violence is when people are fighting and stabbing others or there is a gunshot, the children run out of the door. You ask them what is wrong, they say they are shooting or maybe someone have a gun, then they are running... (Velma) I don't like them to go here at the back like because it's quiet and if it's quiet maybe something sinister happens there to the children and sometimes you find children hanging around there and I say to her she mustn't go to the park... The worst thing of all, [name] doesn't like bad things, it affects her wrongly...It's as if that thing happened to her, she becomes frightened. (Nosipho)

I don't feel like it is safe for my children. They shoot each other and there is a guy that stays at the white house who is rumoured to be a thug and we are scared of that. From time to time you will hear that there is a child that has been raped, so we are not safe... He feels bad because if he encounters such activities, he does not forget about them. He will keep on talking about them, and he is scared. (Yolisa)

Interestingly, some participants stated that safety was not an issue in their community, while others did not perceive the crime in their community to be a problem, even though they gave examples of crime in their community that others might perceive to be severe. Some 
comments suggested that violence and crime is somewhat normalised, and that participants and their children may be desensitised to the violent events to which they and their children are exposed. In some cases, the impact of this violence and crime on their children seemed to be downplayed or underestimated.

There are people who fight but, unless if they witness it themselves when they are out there playing far, but there is nothing going on much here. You might hear from time to time that they took a phone... they know that you don't carry your phone with you when you are going out alone, because they will take it... I don't know how they affect them but they know that you don't take your phone. (Khuselwa)

She talks about especially when she hears the gun shot, then she wants to know why they are there, and I have to explain. But it is not affecting her because if she hears that then she comes inside... She doesn't react what she saw outside, she is not the child like that. (Candice)

When he plays with his friends outside, because some of his friends are physically violent, there are some that are bullies and physically violent, so then he'll come home and say to me so and so hit me, this one hit me or whatever...it's just the kids that are 'amapharaphara' [petty thieves/drug addicts] hanging around the Pakistan shops, and they take the kids' pocket money when they go to the shops... [It's not something that affects your son?] No. (Gladys)

The crime that is here is car break-ins and robbery, you shouldn't walk with a phone in the late hours I can say. There is crime I can say especially with a lot of people around the back... there is nothing that is affecting the kids. (Zintle) 


\section{Resources}

Social support: Apart from the safety concerns, participants spoke about the social support they experienced in their community. This was mostly to do with the caregiving role played by other community members for their child, children from the community playing together, and in some cases, the support they received for their caregiving role. Children playing with other children in the neighbourhood seemed to be encouraged, and appeared to be supported by an understanding that other community members would look out for their child, which is relevant given the safety concerns mentioned above.

She plays with the neighbours they like to play 'school', and the other is 'doctor, doctor'. And then they play 'house'. They play 'you come buy from my shop'. They like the restaurant game she has two friends at home. (Candice)

I meet up with friends and talk to them. If they are financially in a good place, then they'll say 'my brother, I can borrow you this amount of money, and when you are able to do so you can reimburse me'. So that's how we help each other out. (Siya)

Despite these perceptions of social support in the community, a number of participants felt that there was either a lack of community programmes available to assist them with the challenges they were facing, or assistance from these programmes was limited.

There is no one that is helping me it is only me. [Not even an organisation around?] No, there is nobody, there is no people. (Linda)

[Are there no organisations that help to influence children to love school?] ...No we don't have that other than when they form groups themselves and do activities such as music and so forth, other than that, there is nothing. (Yolisa)

The only thing we have here is the soup kitchen up the road. They go there to get food because they do announce for children to come at 13:00 to come and get something to eat. Then once they have done that, they eat, pray and sing. (Khuselwa) 
Infrastructure: Some participants mentioned community resources, such as parks and libraries, but there were concerns expressed by a few participants regarding the safety of these facilities.

He likes to go to the...park...the library is there, and I take him. (Zelda)

...they no longer go to the park since there are lots of thugs. Because when you are at the park, you can't even hold a phone because you are scared. And also the equipment is broken so there is nothing that they can learn from... There is also a library, but we don't feel safe, more so because we don't know what is happening inside there, we have never been there. (Khuselwa)

Perceptions of community's role in child's development: Related to these available community resources, participants had mixed views about the community's role in their child's development. Some mentioned activities that they would like the community to offer to promote their child's development, and while a few acknowledged that interaction with other children through play was beneficial for their child's development, some participants did not readily recognise these benefits or directly acknowledge the role of the community in developing their child.

... if they had a centre where the kids can go to after school, because our kids wake up and go to school, and when they come back from school, they don't have anything to do, they don't even have homework. (Eunice)

I think they have because they love playing outside but then since I have not paid much attention and have not given myself the chance to see if they can do certain things and be able to identify if they have learned that from the community or from the friends. (Khuselwa) 
You know when it comes to the issue of playing, I don't think that there's anything that he learns out there... it's a matter of them just going to play at the park, there's nothing more to it. (Siya)

\section{Discussion}

The findings of this study have highlighted numerous aspects of the South African family, home and community contexts that promote and undermine ECD and the provision of nurturing care. This aligns with previous work using an ecological framework, that identified similar factors affecting school readiness in South African settings, according to parents and other stakeholders (Munnik \& Smith, 2019). Many of the risks to ECD mentioned directly or indirectly by caregivers in this study were as expected in low-income settings, such as low socioeconomic status, challenging family relationships, crime and violence, and poor infrastructure to support nurturing care and ECD. All of these are threats to the provision of nurturing care (World Health Organization et al., 2018), and can ultimately contribute to the accumulation of adversities that have a detrimental influence on developmental trajectories (Tomlinson et al., 2019; Tomlinson, Hunt, et al., 2021). Furthermore, these risks have been exacerbated by the COVID-19 pandemic, which has disrupted the enabling environments needed for families to provide nurturing care (Tomlinson, Richter, et al., 2021). As previously stated, women in South Africa have been the worst affected by COVID-19 (Spaull et al., 2021), and it is clear from the findings of this study how women carry the heavy burden of caregiving, even though many caregivers seemed to minimise challenges they experience. Although only two caregivers spoke about being diagnosed with depression, available data during the COVID-19 pandemic (Spaull et al., 2021) would suggest that mental health challenges were underreported in this study, or that they are considered to be part of 'normal' life in these settings. 
The impact of violence on ECD is particularly concerning in these low-income South African settings, and this has been documented in the Birth to Twenty Plus study, which also reported high levels of exposure to community violence (Richter et al., 2018). Cumulative exposure to various forms of violence has been shown to negatively impact on various aspects of ECD (McCoy, 2013; McCoy et al., 2015, 2016; McLaughlin \& Sheridan, 2016), as well as the mental health and well-being of children across a range of settings (Abbo et al., 2013; Barbarin et al., 2001; Massad et al., 2017; Skeen et al., 2016; Thabet et al., 2006). Exposure to violence includes physical punishment in the home, ECCE and school settings, which was reported by some caregivers in this study. The use of physical punishment has been reported in another qualitative study with parents in Ghana (Wolf, 2020). Evidence indicates the detrimental impact of physical punishment on ECD in low- and middle-income countries (LMICs) (Cuartas, 2021a, 2021b), and protecting children from maltreatment is a recommendation in the Nurturing Care Framework (World Health Organization et al., 2018). Further evidence from LMICs is needed regarding violence prevention strategies in early childhood, and it has been suggested that a social ecological approach is taken for the conceptualisation of prevention strategies in LMIC settings. These strategies should seek to address cultural norms that contribute to the normalising the physical punishment of children, and should involve fathers (Efevbera et al., 2017).

While the research on the role of fathers is limited in LMICs, two studies in rural settings (Pakistan and South Africa), both using ecological approaches, have highlighted fathers' supportive role in parenting, providing, decision-making, and stimulating early learning (Jeong et al., 2018; Mncanca \& Okeke, 2016). Given the perspectives shared by caregivers in this study - including dysfunctional relationships and absent fathers, and the predominance of single, mostly female caregivers - involving fathers in low-income South African settings would be extremely challenging. However, the evidence suggests that this 
would be a worthy investment for ECD in this country. For caregivers and ECCE practitioners, guidance on supportive (instead of harsh) discipline in challenging circumstances would be beneficial for the provision of nurturing care and for the development of young children in these settings. Since routines and boundaries were seldom discussed by caregivers in this study, these should be included in the guidance provided, given these provide a sense of security and safety for the child (Britto et al., 2017).

In terms of the social, policy, and historical 'layers' of the social ecological model as they pertain to the findings of this study, it is necessary to highlight aspects of the broader South African context (included in Figure 1), even though these were not specifically articulated by caregivers. These can contribute substantially to the accumulated adversities mentioned above. While there have been many policy gains in post-apartheid South Africa, implementation has lagged, particularly with regards to health, early learning, education and social development policies affecting young children (Hall et al., 2019). Furthermore, systems instituted under apartheid, particularly spatial injustice, continue to place lowincome communities at a socioeconomic disadvantage (Strauss, 2019), compounding the historical and intergenerational trauma that marginalised communities have already experienced since apartheid (Adonis, 2016).

Despite public discourse about systemic racism and 'white privilege', and even though white people make up less than $10 \%$ of the total population according to the last national census (Statistics South Africa, 2012), socioeconomic inequalities in South Africa remain firmly along racial lines, with white South Africans faring the best by far (Statistics South Africa, 2019). The term 'structural violence' is apt for describing these systemic issues in South Africa (Forde et al., 2021). First coined in the late 1960s, it refers to the social structures, including economic and political systems, that prevent individuals, families, communities and societies from meeting their full potential (Galtung, 1969). It has also been 
defined as "social arrangements that put individuals and populations in harm's way" (Farmer et al., 2006). Since structural violence can lead to overt violence (Lee, 2019), it is imperative that these social structures and arrangements are considered when investigating the factors influencing ECD in South Africa, and when strategies are developed to promote ECD and the provision of nurturing care, especially in settings where violence is prevalent.

In spite of all these challenges, it is apparent that the caregivers in this study have made a significant effort to provide nurturing care. The loving way in which they spoke about their children and their support for their child's autonomy suggest that they are attempting to be responsive in their caregiving. They did not dwell on their children's behavioural challenges, but it was clear for some that these challenges were due to the adversities in their environment. These caregivers acknowledged their role in their child's development, and reported engaging in stimulating activities that would be beneficial for their child's early learning. Caregivers also seemed to place value on development and early learning, which is something that should be capitalised on in future intervention efforts. These findings are similar to another South African study with parents of younger children in a low-income setting, who acknowledged the importance of their role in their child's development and the need for children need to thrive in the early years of life (Adebiyi et al., 2021). A study with parents of preschool children in Ghana also had similar findings (Wolf, 2020). In terms of choices around early learning and educational opportunities, caregivers in this study valued quality, which is encouraging, although their choices appeared to be largely driven by availability of resources. Other studies in LMICs have similarly highlighted the influence of resources and quality in choices about ECCE environments, particularly in terms of childteacher interaction (Malik, 2021; Wolf, 2020).

Caregivers' sense of responsibility to provide for and protect their children, often at their own expense, was evident in this study and relates to various components of nurturing 
care (health, nutrition, safety and security). Their resourcefulness was also noteworthy, given their stated resource challenges, and this aligns with findings about children's resourcefulness in play in similar settings (Bartie et al., 2016). Similar findings about providing and protecting have been found in other qualitative studies with parents in low-income settings (Quint et al., 2018; Wolf, 2020). In these settings, it is not unusual for parents to worry about providing for their children, and try to protect their children from poverty and the dangers within their community, such as crime and violence. It is common for children to be aware of the poverty their family is experiencing, and come to know that it means 'going without'. This has been found to cause psychological stress for both parents and children, and parents are typically aware of the impact of community risks on the child (Quint et al., 2018).

The fact that some caregivers underestimated and/or downplayed the impact of some community risks in this study warrants further exploration and intervention. It is possible that this may be a result of the resilience developed by caregivers to cope with their environment, since it has been stated that in South Africa, "most families must function under incredibly difficult circumstances. Yet families in South Africa are characterised by significant resilience" (Department of Social Development, 2021). However, the extent to which this resilience is healthy or dysfunctional needs to be established. The structural violence, historical and intergenerational trauma experienced in low-income South African settings (Adonis, 2016) suggests that some of this resilience - although potentially necessary to survive - may be maladaptive. It has been argued that within low-income settings, "trauma begets trauma, trauma begets poverty, poverty begets poverty, poverty begets trauma, and the cycle goes on" (Gelkopf, 2018). Taking this all into account, support for caregivers' and children's mental health to deal with this trauma in healthy ways is essential in these settings in order to break the trauma-poverty cycle. Caregivers emphasised the importance of social support in their family and community, and this should form a critical component of 
interventions to support caregivers (Department of Social Development, 2021). While the support of community-based organisations and the community's role in promoting children's development did not feature prominently in the interviews, from a social ecological perspective, these organisations and other community structures should also form part of these support networks.

This study had some limitations and strengths. A limitation of this study was that some of the interviews were short in duration, and consequently did not explore all relevant issues in depth. Although the interviews were conducted in the home language of participants, it is possible that the educational level of some participants may have influenced their ability and/or confidence to fully articulate their views. Another limitation is that this study did not explore all layers of the social ecological model in the interviews; this could be taken up in future research. The exploratory nature of this study was a strength as it helped to uncover salient issues for caregivers relevant to the social ecological model, and it helped to provide a nuanced understanding of the complex interrelationships between layers of the social ecological model in low-income South African settings. Furthermore, individual interviews were conducive to the sharing of caregivers' personal perspectives and narratives; these are important, in addition to understanding collective experience in these communities, which could have been obtained from focus group discussions.

In conclusion, the findings from this study indicate that the social ecological model provides a holistic and contextually relevant perspective for understanding multiple factors influencing ECD in low-income South African settings, both in terms of risks and protective factors. As previously maintained (Department of Social Development, 2021), this perspective acknowledges the complexity of relationships between families, communities and society in South Africa, and this complexity has been conveyed in the caregivers' perspectives presented in this paper. These qualitative findings provide insight into the 
current priorities, challenges and levels of understanding of caregivers in these settings. While there are numerous structural issues that need addressing in South Africa, there are also numerous opportunities for intervening in families and communities to holistically address risks and amplify protective factors for promoting nurturing care and ECD in the most vulnerable children of this country. Insights gleaned from this study can inform intervention strategies to support caregivers (including fathers) in their role of developing, nurturing, providing, protecting, and disciplining their young children. These strategies should connect with community support networks and resources, and should incorporate the mental health of caregivers in order to assist them with carrying the caregiving load in a way that promotes healthy resilience and nurturing connections with their child.

\section{References}

Abbo, C., Kinyanda, E., Kizza, R. B., Levin, J., Ndyanabangi, S., \& Stein, D. J. (2013). Prevalence, comorbidity and predictors of anxiety disorders in children and adolescents in rural north-eastern Uganda. Child and Adolescent Psychiatry and Mental Health, 7. psyh. https://doi.org/10.1186/1753-2000-7-21

Adebiyi, B. O., Goldschmidt, T., Benjamin, F., Sonn, I. K., \& Roman, N. V. (2021). Exploring the Perspectives of South African Parents and Primary Caregivers Living in Low-Income Communities on What Children Need to Thrive within the First 1000 Days of Life. Children, 8, 483. https://doi.org/10.3390/children8060483

Adonis, C. K. (2016). Exploring the salience of intergenerational trauma among children and grandchildren of victims of apartheid-era gross human rights violations. Indo-Pacific Journal of Phenomenology, 16(2), 1-17. https://doi.org/10.1080/20797222.2016.1184838 
Barbarin, O. A., Richter, L., \& deWet, T. (2001). Exposure to violence, coping resources, and psychological adjustment of South African children. Am J Orthopsychiatry, 71(1), 16-25. https://doi.org/10.1037/0002-9432.71.1.16

Bartie, M., Dunnell, A., Kaplan, J., Oosthuizen, D., Smit, D., van Dyk, A., Cloete, L., \& Duvenage, M. (2016). The Play Experiences of Preschool Children from a Lowsocio-economic Rural Community in Worcester, South Africa. Occupational Therapy International, 23(2), 91-102. https://doi.org/10.1002/oti.1404

Black, M. M., Walker, S. P., Fernald, L. C. H., Andersen, C. T., DiGirolamo, A. M., Lu, C., McCoy, D. C., Fink, G., Shawar, Y. R., Shiffman, J., Devercelli, A. E., Wodon, Q. T., Vargas-Barón, E., \& Grantham-McGregor, S. (2017). Early childhood development coming of age: Science through the life course. The Lancet, 389(10064), 77-90. https://doi.org/10.1016/S0140-6736(16)31389-7

Braun, V., \& Clarke, V. (2021). Can I use TA? Should I use TA? Should I not use TA? Comparing reflexive thematic analysis and other pattern-based qualitative analytic approaches. Counselling and Psychotherapy Research, 21(1), 37-47. https://doi.org/10.1002/capr.12360

Breen, A., Daniels, K., \& Tomlinson, M. (2015). Children's experiences of corporal punishment: A qualitative study in an urban township of South Africa. Child Abuse \& Neglect, 48, 131-139. https://doi.org/10.1016/j.chiabu.2015.04.022

Britto, P. R., Lye, S. J., Proulx, K., Yousafzai, A. K., Matthews, S. G., Vaivada, T., PerezEscamilla, R., Rao, N., Ip, P., Fernald, L. C. H., MacMillan, H., Hanson, M., Wachs, T. D., Yao, H., Yoshikawa, H., Cerezo, A., Leckman, J. F., \& Bhutta, Z. A. (2017). Nurturing care: Promoting early childhood development. The Lancet, 389(10064), 91-102. https://doi.org/10.1016/S0140-6736(16)31390-3 
Bronfenbrenner, U. (1977). Toward an experimental ecology of human development. American Psychologist, 32(7), 513-531. https://doi.org/10.1037/0003-066X.32.7.513

Cook, C. J., Howard, S. J., Scerif, G., Twine, R., Kahn, K., Norris, S. A., \& Draper, C. E. (2019). Associations of physical activity and gross motor skills with executive function in preschool children from low-income South African settings. Developmental Science, 22(5), e12820. https://doi.org/10.1111/desc.12820

Cuartas, J. (2021a). The effect of spanking on early social-emotional skills. Child Development, cdev.13646. https://doi.org/10.1111/cdev.13646

Cuartas, J. (2021b). Corporal punishment and early childhood development in 49 low- and middle-income countries. Child Abuse \& Neglect, 120, 105205. https://doi.org/10.1016/j.chiabu.2021.105205

Daniels, K., Forinder, U., Clarke, M., Snyman, S., \& Ringsberg, K. C. (2016). Preschool children's healthy lifestyles: South African parents' and preschool staff perceptions. Health Education Journal, 75(8), 897-910.

Dawes, A., Biersteker, L., Girdwood, E., Snelling, M., \& Horler, J. (2020). The Early Learning Programme Outcomes study: Research insights. Innovation Edge and Ilifa Labantwana. http://elom.org.za/wp-content/uploads/2020/10/InnovationInsights_ELPO-General-Report.pdf

Department of Social Development. (2021). Revised White Paper on families in South Africa. Department of Social Development. https://www.gov.za/sites/default/files/gcis_document/202107/44799gon586t.pdf

Draper, C. E., Achmat, M., Forbes, J., \& Lambert, E. V. (2012). Impact of a communitybased programme for motor development on gross motor skills and cognitive function in preschool children from disadvantaged settings. Early Child Development and Care, 182(1), 137-152. https://doi.org/10.1080/03004430.2010.547250 
Draper, C. E., Howard, S. J., \& Rochat, T. J. (2019). Feasibility and acceptability of a homebased intervention to promote nurturing interactions and healthy behaviours in early childhood: The Amagugu Asakhula pilot study. Child: Care, Health and Development, 45(6), 823-831. https://doi.org/10.1111/cch.12714

Draper, C. E., Silubonde, T. M., Mukoma, G., \& van Sluijs, E. M. F. (2022). Perceptions of the South African 24-hour movement guidelines for birth to 5 years: A qualitative study. Journal of Physical Activity \& Health.

Draper, C. E., Tomaz, S. A., Stone, M., Hinkley, T., Jones, R. A., Louw, J., Twine, R., Kahn, K., \& Norris, S. A. (2017). Developing Intervention Strategies to Optimise Body Composition in Early Childhood in South Africa. BioMed Research International, 2017, 1-13. https://doi.org/10.1155/2017/5283457

Efevbera, Y., McCoy, D. C., Wuermli, A. J., \& Betancourt, T. S. (2017). Early Childhood Development Plus Violence Prevention in Low- and Middle-Income Countries: A Qualitative Study. Children \& Society, 31(2), 98-109. https://doi.org/10.1111/chso.12169

Farmer, P. E., Nizeye, B., Stulac, S., \& Keshavjee, S. (2006). Structural Violence and Clinical Medicine. PLoS Medicine, 3(10), e449. https://doi.org/10.1371/journal.pmed.0030449

Forde, S., Kappler, S., \& Björkdahl, A. (2021). Peacebuilding, Structural Violence and Spatial Reparations in Post-Colonial South Africa. Journal of Intervention and Statebuilding, 15(3), 327-346. https://doi.org/10.1080/17502977.2021.1909297

Galtung, J. (1969). Violence, Peace, and Peace Research. Journal of Peace Research, 6(3), 167-191. 
Gelkopf, M. (2018). Social injustice and the cycle of traumatic childhood experiences and multiple problems in adulthood. JAMA Network Open, 1(7), e184488. https://doi.org/10.1001/jamanetworkopen.2018.4488

Hall, K., Sambu, W., Almeleh, C., Mabaso, C., Giese, S., \& Proudlock, P. (2019). South African Early Childhood Review 2019. Children's Institute, University of Cape Town and Ilifa Labantwana. http://childrencount.uct.ac.za/uploads/publications/SA\%20ECR_2019.pdf

Howard, S. J., Cook, C. J., Everts, L., Melhuish, E., Scerif, G., Norris, S., Twine, R., Kahn, K., \& Draper, C. E. (2020). Challenging socioeconomic status: A cross-cultural comparison of early executive function. Developmental Science, 23(1). https://doi.org/10.1111/desc.12854

Jeong, J., Siyal, S., Fink, G., McCoy, D. C., \& Yousafzai, A. K. (2018). "His mind will work better with both of us": A qualitative study on fathers' roles and coparenting of young children in rural Pakistan. BMC Public Health, 18(1), 1274. https://doi.org/10.1186/s12889-018-6143-9

Klingberg, S., Sluijs, E. M. F. van, \& Draper, C. E. (2020). “The thing is, kids don't grow the same": Parent perspectives on preschoolers' weight and size in Soweto, South Africa. PLOS ONE, 15(4), e0231094. https://doi.org/10.1371/journal.pone.0231094

Klingberg, S., van Sluijs, E. M., \& Draper, C. E. (2021). Parent perspectives on preschoolers' movement and dietary behaviours: A qualitative study in Soweto, South Africa. Public Health Nutrition, 24(12), 3637-3647. https://doi.org/10.1017/S1368980020003730

Klingberg, S., van Sluijs, E. M. F., Jong, S. T., \& Draper, C. E. (2021). Can public sector community health workers deliver a nurturing care intervention in South Africa? The 
Amagugu Asakhula feasibility study. Pilot and Feasibility Studies, 7(1), 60. https://doi.org/10.1186/s40814-021-00802-6

Lee, B. X. (2019). Structural violence. In Violence: An interdisciplinary approach to causes, consequences, and cures (pp. 123-142). John Wiley \& Sons, Ltd. https://doi.org/10.1002/9781119240716.ch7

Lessing, A. C., \& Witt, M. W. D. (2005). An investigation into the early literacy skills of Grade R Second-language (L2) learners in South Africa. In Africa Education Review (Vol. 2, Issue 2, pp. 242-257).

Malik, S. (2021). Parental Involvement in Early Childhood Education in Punjab: A Qualitative Study. Revista Gestão Inovação e Tecnologias, 11(3), 785-797. https://doi.org/10.47059/revistageintec.v11i3.1975

Massad, S., Khammash, U., \& Shute, R. (2017). Political violence and mental health of Bedouin children in the West Bank, Palestine: A cross-sectional study. Med Confl Surviv, 33(3), 188-206. https://doi.org/10.1080/13623699.2017.1368307

McCoy, D. C. (2013). Early Violence Exposure and Self-Regulatory Development: A Bioecological Systems Perspective. Human Development, 56(4), 254-273. https://doi.org/10.1159/000353217

McCoy, D. C., Raver, C. C., \& Sharkey, P. (2015). Children's Cognitive Performance and Selective Attention Following Recent Community Violence. Journal of Health and Social Behavior, 56(1), 19-36. https://doi.org/10.1177/0022146514567576

McCoy, D. C., Roy, A. L., \& Raver, C. C. (2016). Neighborhood crime as a predictor of individual differences in emotional processing and regulation. Developmental Science, 19(1), 164-174. https://doi.org/10.1111/desc.12287 
McLaughlin, K. A., \& Sheridan, M. A. (2016). Beyond Cumulative Risk: A Dimensional Approach to Childhood Adversity. Current Directions in Psychological Science, 25(4), 239-245. https://doi.org/10.1177/0963721416655883

Mncanca, M., \& Okeke, C. I. O. (2016). Positive Fatherhood: A Key Synergy for Functional Early Childhood Education in South Africa. Journal of Sociology and Social Anthropology, 7(4), 221-232. https://doi.org/10.1080/09766634.2016.11885720

Munnik, E., \& Smith, M. (2019). Contextualising school readiness in South Africa: Stakeholders' perspectives. South African Journal of Childhood Education, 9(1). https://doi.org/10.4102/sajce.v9i1.680

Naudé, H., Pretorius, E., \& Viljoen, J. (2003). The Impact of Impoverished Language Development on Preschoolers' Readiness-To-Learn During the Foundation Phase. Early Child Development and Care, 173(2-3), 271-291. https://doi.org/10.1080/03004430303098

Pretorius, E., \& Naudé, H. (2002). A Culture in Transition: Poor Reading and Writing Ability Among Children in South African Townships. Early Child Development and Care, 172(5), 439-449. https://doi.org/10.1080/03004430214552

Quint, J., Griffin, K. M., Kaufman, J., Landers, P., \& Utterback, A. (2018). Experiences of parents and children living in poverty: A review of the qualitative literature (OPRE Report 2018-30). Office of Planning, Re- search, and Evaluation, Administration for Children and Families, U.S. Department of Health and Human Services.

Richter, L. M., Mathews, S., Kagura, J., \& Nonterah, E. (2018). A longitudinal perspective on violence in the lives of South African children from the Birth to Twenty Plus cohort study in Johannesburg-Soweto. South African Medical Journal, 108(3), 181. https://doi.org/10.7196/SAMJ.2018.v108i3.12661 
Shields, N., Nadasen, K., \& Pierce, L. (2008). The effects of community violence on children in Cape Town, South Africa. Child Abuse \& Neglect, 32(5), 589-601. https://doi.org/10.1016/j.chiabu.2007.07.010

Simons, A., Koekemoer, K., Niekerk, A. van, \& Govender, R. (2018). Parental supervision and discomfort with children walking to school in low-income communities in Cape Town, South Africa. Traffic Injury Prevention, 19(4), 391-398. https://doi.org/10.1080/15389588.2017.1420904

Skeen, S., Macedo, A., Tomlinson, M., Hensels, I. S., \& Sherr, L. (2016). Exposure to violence and psychological well-being over time in children affected by HIV/AIDS in South Africa and Malawi. AIDS Care, 28 Suppl 1(sup1), 16-25. https://doi.org/10.1080/09540121.2016.1146219

Slemming, W., Cele, R., \& Richter, L. M. (2021). Quality of early childcare in the home and cognitive development at age 5: Results from the South African birth to Twenty Plus cohort study. Early Child Development and Care, O(0), 1-14. https://doi.org/10.1080/03004430.2020.1868449

Spaull, N., Daniels, R. C., Ardington, C., Branson, N., Breet, E., Bridgman, G., Brophy, T., Burger, R., Burger, R., Casale, D., English, R., Espi, G., Hill, R., Hunt, X., Ingle, K., Kerr, A., Kika, J., Köhler, T., Kollamparambil, U., ... Turok, I. (2021). Synthesis Report: NIDS-CRAM Wave 5 (p. 13). https://cramsurvey.org/wpcontent/uploads/2021/07/1.-Spaull-N.-Daniels-R.-C-et-al.-2021-NIDS-CRAM-Wave5-Synthesis-Report.pdf

Spaull, N., \& Kotze, J. (2015). Starting behind and staying behind in South Africa. International Journal of Educational Development, 41, 13-24. https://doi.org/10.1016/j.ijedudev.2015.01.002 
Statistics South Africa. (2012). Census 2011. Statistics South Africa. https://www.statssa.gov.za/publications/P03014/P030142011.pdf

Statistics South Africa. (2019). Inequality trends in South Africa: A multidimensional diagnostic of inequality. Statistics South Africa. http://www.statssa.gov.za/publications/Report-03-10-19/Report-03-10-192017.pdf

Strauss, M. (2019). A historical exposition of spatial injustice and segregated urban settlement in South Africa. Fundamina, 25(2). https://doi.org/10.17159/2411$7870 / 2019 / \mathrm{v} 25 \mathrm{n} 2 \mathrm{a} 6$

Thabet, A. A., Karim, K., \& Vostanis, P. (2006). Trauma exposure in pre-school children in a war zone. Br J Psychiatry, 188, 154-158. https://doi.org/10.1192/bjp.188.2.154

Tomaz, S. A., Okely, A. D., van Heerden, A., Vilakazi, K., Samuels, M.-L., \& Draper, C. E. (2020). The South African 24-hour movement guidelines for birth to 5 years: Results from the stakeholder consultation. Journal of Physical Activity and Health, 17(1), 126-137. https://doi.org/10.1123/jpah.2019-0188

Tomlinson, M., Hunt, X., Daelmans, B., Rollins, N., Ross, D., \& Oberklaid, F. (2021). Optimising child and adolescent health and development through an integrated ecological life course approach. BMJ, m4784. https://doi.org/10.1136/bmj.m4784

Tomlinson, M., Richter, L., \& Slemming, W. (2021). What the science of child and adolescent development contributes to understanding the impacts of COVID-19. South African Journal of Science, 117(1/2). https://doi.org/10.17159/sajs.2021/8876

Tomlinson, M., Ross, D. A., Bahl, R., Rollins, N., Daelmans, B., Simon, J., \& Costello, A. (2019). What will it take for children and adolescents to thrive? The Global Strategy for Women's, Children's, and Adolescents' Health. The Lancet Child \& Adolescent Health, 3(4), 208-209. https://doi.org/10.1016/S2352-4642(19)30004-5 
Tracy, S. J. (2010). Qualitative Quality: Eight “Big-Tent” Criteria for Excellent Qualitative Research. Qualitative Inquiry, 16(10), 837-851. https://doi.org/10.1177/1077800410383121

Trude, A. C. B., Richter, L. M., Behrman, J. R., Stein, A. D., Menezes, A. M. B., \& Black, M. M. (2021). Effects of responsive caregiving and learning opportunities during preschool ages on the association of early adversities and adolescent human capital: An analysis of birth cohorts in two middle-income countries. The Lancet Child \& Adolescent Health, 5(1), 37-46. https://doi.org/10.1016/S2352-4642(20)30309-6 VERBI Software. (2019). MAXQDA 2020. VERBI Software. https://www.maxqda.com/ von Fintel, D., \& Richter, L. (2019). Intergenerational transfer of health inequalities: Exploration of mechanisms in the Birth to Twenty cohort in South Africa. BMJ Global Health, 4(5), e001828. https://doi.org/10.1136/bmjgh-2019-001828

Vorster, A., Sacks, A., Amod, Z., Seabi, J., \& Kern, A. (2016). The everyday experiences of early childhood caregivers: Challenges in an under-resourced community. South African Journal of Childhood Education, 6(1), 9. https://doi.org/10.4102/sajce.v6i1.257

Wills, G., \& Kika-Mistry, J. (2021). Early Childhood Development in South Africa during the COVID-19 Pandemic: Evidence from NIDS-CRAM Waves 2-5 (p. 32). https://cramsurvey.org/wp-content/uploads/2021/07/14.-Wills-G-_-Kika-Mistry-J.2021-Early-Childhood-Development-in-South-Africa-during-the-n-COVID-19pandemic-Evidence-from-NIDS-CRAM-Waves-2-5.pdf

Wolf, S. (2020). “Me I don’t really discuss anything with them”: Parent and teacher perceptions of early childhood education and parent-teacher relationships in Ghana. International Journal of Educational Research, 99, 101525. https://doi.org/10.1016/j.ijer.2019.101525 
World Health Organization, United Nations Children's Fund, \& World Bank Group. (2018). Nurturing care for early childhood development: A framework for helping children survive and thrive to transform health and human potential. World Health Organization.

https://apps.who.int/iris/bitstream/handle/10665/272603/9789241514064-eng.pdf 